\title{
O referencial de vulnerabilidade ao HIV/AIDS aplicado às famílias: um exercício reflexivo
}

\author{
THE HIVIAIDS VULNERABILITY FRAMEWORK APPLIED TO FAMILIES: A REFLECTION \\ EL REFERENCIAL DE VULNERABILIDAD AL HIVIAIDS APLICADO A LAS FAMILIAS: UN \\ EJERCICIO REFLEXIVO
}

\author{
Diego Schaurich ${ }^{1}$, Hilda Maria Barbosa de Freitas ${ }^{2}$
}

\section{RESUMO}

Objetiva-se realizar um exercício reflexivo acerca das vulnerabilidades que se apresentam no contexto das famílias que convivem com o Vírus da Imunodeficiência Humana/Síndrome da Imunodeficiência Adquirida (HIV/Aids), tendo como fundamentação a literatura pertinente. Para tanto, buscou-se tecer considerações em relação à pluralidade das famílias na contemporaneidade, bem como apresentar as compreensões e desdobramentos do referencial de vulnerabilidade à epidemia da Aids. Por fim, foram descritas aproximações e reflexões referentes às vulnerabilidades à infecção pelo HIV e/ou adoecimento por Aids a que estão expostas as famílias, em seus planos individual, social e programático. Conclui-se a enorme importância de se conhecer estas vulnerabilidades específicas vivenciadas pelas famílias, a fim de que se possa nortear e desenvolver as ações de cuidado em saúde.

\section{DESCRITORES}

\section{Família}

Síndrome da Imunodeficiência Adquirida Vulnerabilidade HIV

\begin{abstract}
The objective of this study is to reflect upon the vulnerabilities experienced by the families dealing with the Human Immunodeficiency Virus/Acquired Immunodeficiency Syndrome (HIV/Aids), and is based on the pertinent literature. To do this, we attempted to propose consideration related to the plurality of families in contemporaneity, and present the understandings and development regarding the vulnerability framework to the Aids epidemics. Finally, the study presents a description of the reflections made about the vulnerabilities to HIV and/or falling ill with Aids to which the families are exposed to in their personal, social and pragmatic levels. In conclusion, it is emphasized that knowing these specific vulnerabilities experienced by the families is essential in order to guide and develop the health care actions.
\end{abstract}

DESCRIPTORS
Family
Acquired Immunodeficiency Syndrome
Vulnerability
HIV

\section{RESUMEN}

Se objetiva realizar un ejercicio reflexivo acerca de vulnerabilidades que se presentan en contexto de familias convivientes con el Virus de Inmunodeficiencia Humana / Síndrome de Inmunodeficiencia Adquirida (HIV/Aids), teniendo como fundamento la literatura pertinente. Para ello se buscó tejer consideraciones en relación a la pluralidad de las familias en la contemporaneidad, así como presentar las comprensiones y desdoblamientos del referencial de vulnerabilidad a la epidemia de Aids. Finalmente, se describieron aproximaciones y reflexiones referentes a las vulnerabilidades a la infección por HIV y/o padecimientos por Aids a los que están expuestas las familias, en planos individual, social y programático. Se concluye creyendo en la importancia de conocer tales vulnerabilidades específicas experimentadas por las familias, a fin de que se pueda orientar y desarrollar acciones de cuidado de la salud.

\section{DESCRIPTORES}

Familias

Síndrome de la Inmunodeficiencia Adquirida Vulnerabilidad

$\mathrm{VIH}$

\footnotetext{
${ }_{1}^{1}$ Doutorando pelo Programa de Pós-Graduação da Escola de Enfermagem da Universidade Federal do Rio Grande do Sul. Professor Assistente do Curso de Enfermagem do Centro Universitário Franciscano. Membro do Núcleo de Estudos do Cuidado de Enfermagem. Membro do Grupo de Cuidado à Saúde das Pessoas, Famílias e Sociedade da Universidade Federal de Santa Maria. Porto Alegre, RS, Brasil. eu_diegosch@hotmail.com 2 Mestre em Enfermagem pela Escola de Enfermagem da Universidade Federal do Rio Grande do Sul. Professor Assistente do Centro Universitário Franciscano. Membro do Grupo de Estudos e Pesquisa em Empreendedorismo Social e Saúde. Santa Maria, RS, Brasil. hildasame@gmail.com
} 


\section{INTRODUÇÃO}

Atualmente, diferentes áreas do conhecimento têm voltado suas atividades de investigação para o contexto das famílias, pois vários estudiosos ${ }^{(1-3)}$ têm constatado que é na e a partir da família que a produção de saúde e de doença acontece, além de ser uma das responsáveis pelas ações de promoção, prevenção e assistência/tratamento de seus membros. Em especial, as disciplinas da saúde têm se interessado em compreender as transformações, adaptações e organizações que vêm ocorrendo ao longo dos tempos e suas implicações e desafios para o cuidado na saúde e na doença.

Neste contexto, vale destacar o surgimento, no início de 1980, de uma nova doença - a Aids -, até então sem tratamento e incurável, que atingiu homossexuais do sexo masculino, profissionais do sexo, usuários de drogas injetáveis e portadores de hemofilia. Neste momento, inúmeras famílias foram afetadas e discriminadas, muito em virtude da falta de conhecimento acerca das formas de transmissão viral, das poucas iniciativas governamentais de prevenção e controle e do pânico instalado na sociedade. Contudo, foi com a mudança do perfil epidemiológico, demonstrada pela intensificação dos processos de heterossexualização, feminização e juvenização, que se percebeu estar a família vulnerável ao HIV/Aids.

Faz-se importante, então, ressaltar que as famílias apresentam vulnerabilidades que estão relacionadas a elementos que compõem os planos individual, social e programático ${ }^{(4-5)}$. Tem-se, assim, como objetivo realizar um exercício reflexivo acerca das vulnerabilidades que se apresentam no contexto das famílias que convivem com a epidemia da Aids.

\section{FAMÍLIAS E A EPIDEMIA DA AIDS}

A família configura-se como uma instituição essencial ao ser humano, pois é por intermédio dela que passa a existir como pessoa, tendo a possibilidade de desenvolver suas potencialidades e capacidades, bem como de reconhecer suas necessidades e limitações. O núcleo familiar é responsável pelo acolhimento, reconhecimento, proteção e cuidado do ser humano, principalmente nos primeiros anos de vida em que revela-se frágil e vulnerável aos fenômenos que acontecem nas esferas biológica, psicológica, educacional, social e histórica.

Pode-se considerar que as evoluções tecnológica e científica, aliadas ao processo de globalização, têm contribuído com as transformações que se produzem na vida das pessoas, nas relações entre estas e o contexto social, no ciclo familiar e, também, no cotidiano das organizações familiares. Estas modificações têm sua gênese em uma série de movimentos que se processaram, principalmente, no século XX e que têm reorientado o cuidado em saúde.

Dentre estas transformações, destaca-se, por exemplo, o aumento da expectativa de vida da população, os movimentos gay e feminista, o surgimento dos métodos de anticoncepção que trouxe como consequência a desvinculação do ato sexual da função de procriação e a elaboração dos estatutos da criança e do adolescente e o do idoso. Entende-se, assim, que estes acontecimentos repercutiram na sociedade e têm influenciado nas modificações que ocorreram na estrutura e organização das famílias.

Atualmente, há tentativas de ressignificação no modo de compreender e perceber estes grupos humanos e, para tanto, o que se entende por famílias precisa ir além de um conceito pré-estabelecido, delimitado e generalizante. Acredita-se que ao invés de um conceito que a defina, a busca deve ser por descrições, pois é possível descrever as várias estruturas ou modalidades assumidas pela família através dos tempos, mas não defini-la ou encontrar algum elemento comum a todas as formas com que se apresenta este agrupamento humano ${ }^{(6)}$.

Uma das descrições possíveis às famílias é que revelam-se unidades dinâmicas, constituídas por indivíduos que, a priori, percebem-se como grupo e têm um movimento contínuo de relações (afetivas, econômicas, educacionais) entre seus membros e destes com as demais pessoas e instituições sociais. Ainda, convivem por um tempo com uma organização e estrutura em transformação, firmando objetivos comuns e construindo uma história de vida ${ }^{(3,6)}$.

É preciso considerar que existe uma multiplicidade de manifestações assumidas pelas famílias para, então, conhecer e compreender estes muitos modos com que elas se apresentam. Isto é, deve-se pensar famílias no plural (e não mais como entidades fixas) e que apresentam uma variedade de formas e uma dinamicidade social ${ }^{(1-2)}$. Não se pode falar de família, mas de famílias, para que se possa tentar contemplar a diversidade de relações que convivem na sociedade ${ }^{(1)}$.

Ressalta-se, assim, que as famílias representam unidades de experiência e vivência para seus membros, além de serem significantes no processo de saúde e doença, pois a ocorrência em um dos indivíduos acaba por afetar todo o grupo, gerando momentos de crise. Estas crises ensejam o acúmulo de experiências e uma melhor definição de objetivos $^{(6)}$, devendo ser compreendidas como fatores reordenativos e readaptativos indispensáveis ao desenvolvimento do ser humano, das famílias e das sociedades.

E é compreendendo este sentido de crise que se deve analisar o vivido pelas famílias. Questões como os diálo- 
gos sobre sexo e sexualidade sempre necessários, a separação e o divórcio cada vez mais frequentes, a homossexualidade que deixou de ser algo pertencente apenas à família do outro, o estabelecimento de relações que precedem o casamento e o (con)viver com a complexidade das doenças crônicas (como a Aids), são alguns fenômenos que permeiam o viver das famílias e que podem ser considerados geradores de crises.

Sendo assim, ao se analisar os dados epidemiológicos do Ministério da Saúde ${ }^{(7)}$, pode-se constatar que existem 544.846 casos de Aids notificados até junho de 2009, sendo 356.427 no sexo masculino e 188.396 no sexo feminino. Há, ainda, 14.184 notificações em menores de 13 anos de idade, sendo $86,1 \%$ destas infecções por transmissão vertical (da mãe para o/a filho/a), e 11.786 casos de Aids entre adolescentes (de 13 a 19 anos). Estes dados, no entanto, revelam parcialmente a realidade, uma vez que as ações de cuidado (promoção, prevenção, assistência/tratamento) não devem ser pensadas somente para as pessoas que vivem com HIV/Aids, mas também para aquelas que convivem, ou seja, que são afetadas por esta epidemia, como os demais membros familiares, amigos/as, vizinhos/as, entre outros.

No contexto HIV/Aids percebe-se que os pais biológicos estão sendo substituídos pelos avós, irmãos, pais adotivos, vizinhos, o que reforça a necessidade de transcender a visão de famílias formadas por membros que apresentam consanguinidade. Para além disso, tem-se as questões relativas à orfandade a que estão suscetíveis crianças e adolescentes, em virtude, entre outras causas, da cronicidade da doença e da complexidade do tratamento antirretroviral entre os adultos que culmina, na grande maioria das vezes, no ainda elevado número de óbitos relacionados à Aids ${ }^{(8)}$. E a partir desta situação, as crianças e adolescentes passam a viver em instituições de apoio/abrigo, constituindo, nestes locais, novos agrupamentos familiares.

As famílias, então, podem ser consideradas ambientes de suporte, fontes de carinho, responsabilidade, disponibilidade, felicidade ${ }^{(9)}$, respeitando-se as potencialidades e as limitações em (conseguir) ajudar, inerentes a cada uma delas. Percebe-se, assim, a importância de o cuidado em saúde ser desenvolvido não só ao indivíduo que tem Aids, mas também a sua família, principalmente, por dois motivos: primeiro pelo fato de que será a família, no seu cotidiano, a responsável, na maioria das vezes, pelo auxílio, suporte e cuidados ao membro que está infectado/adoentado, e, segundo, porque a família precisará de auxílio e suporte e, para tanto, é imprescindível conhecê-la em sua estrutura, seus recursos e suas necessidades.

Em consonância com as demais áreas da saúde, a enfermagem vem direcionando seu foco de atenção e cuidado para as famílias, o que tem repercutido no aumento das investigações científicas e da produção de novos (e outros) saberes. $O$ crescente corpo de conhecimento presente na literatura de enfermagem significa progresso neste campo de conhecimento, sendo que as principais contribuições dizem respeito a três eixos, quais sejam: a experiência da doença (seus significados e impactos na vida cotidiana familiar), o contexto de cuidado (cenários de cuidar em que as famílias estão inseridas) e as intervenções (estratégias de trabalhos e ações com as famílias que vivenciam a doença) $)^{(3)}$.

Diante destas considerações, pode-se compreender que a vulnerabilidade da família em uma situação de doença pode ser definida como se sentir ameaçada em sua autonomia, sob pressão da doença ${ }^{(10)}$. Sendo assim, em virtude destes entendimentos e destas transformações que vêm se fazendo presentes na organização das famílias ao longo dos tempos, aliadas às questões complexas que são inerentes à epidemia HIV/Aids, observa-se, atualmente, um esforço de pesquisadores e estudiosos em analisar as implicações e repercussões do referencial de vulnerabilidade quando aplicado aos diversos e diferentes agrupamentos familiares.

\section{VULNERABILIDADE: UM REFERENCIAL NO CONTEXTO DA AIDS}

O conceito de vulnerabilidade tem sua origem na área da advocacia internacional pelos Direitos Universais do Homem, estando relacionado a grupos ou indivíduos fragilizados, tanto jurídica como politicamente, na proteção, promoção e garantia de cidadania ${ }^{(4)}$. Este referencial tem sido utilizado em várias disciplinas do conhecimento e vem ganhando destaque e atenção nas pesquisas, ações e políticas relacionadas à epidemia HIV/Aids.

Este conceito surge para suprir lacunas deixadas pelos conceitos de grupo e comportamento de risco, amplamente divulgados e associados no período inicial da infecção pelo HIV. Isto ocorreu, principalmente, pela insuficiência destes em possibilitar compreensões relacionadas aos rumos da epidemia, em propiciar explicações para além daquelas do tipo causa-e-efeito e em restringir as ações e as políticas públicas trazendo, com isso, ineficazes respostas frente ao avanço epidêmico(11).

Há que se considerar que o conceito de risco, herdado da área da epidemiologia médica, por si só, não possibilita uma visão mais ampla e contextualizada da epidemia da Aids. Ou seja, a utilização conceitual de risco apresenta como foco o indivíduo e as possíveis relações causais existentes entre condições ou eventos patológicos e os não-patológicos ${ }^{(5,12)}$, mais preocupado com a natureza fisiopatológica dos fenômenos de adoecimento, o que limitou, de certa forma, associações entre o individual, o dinâmico processo saúde-doença e o coletivo.

Duas questões podem ser citadas como exemplos que fugiam ao alcance das explicações de risco: qual comportamento arriscado em relação ao HIV apresenta uma mulher dona de casa, em relacionamento estável e com parceiro único e fixo? Ou então: qual comportamento de 
risco à infecção pelo HIV tem um feto em vida intra-uterina? E já no início de 1990 percebe-se as mudanças que vinham ocorrendo nas notificações de Aids e que, assim como estes questionamentos, não obtinham respostas das correlações do conceito de risco, tanto na área de prevenção quanto na de assistência.

E é na busca de explicações e ações frente a estes acontecimentos que emana o constructo de vulnerabilidade, compreendido como um

movimento de considerar a chance de exposição das pessoas ao adoecimento como a resultante de um conjunto de aspectos não apenas individuais, mas também coletivos, contextuais, que acarretam maior suscetibilidade ${ }^{(5)}$,

à infecção e/ou ao adoecimento. Ao utilizar este referencial, há que se considerar a flexibilidade existente entre a teoria e a prática, o individual e o coletivo, a reflexão e a ação, para, então, conseguir contextualizar o indivíduo ou grupo que vivencia situações de vulnerabilidade e buscar respostas mais efetivas e eficazes no combate à epidemia.

A vulnerabilidade pode ser desdobrada em três planos analíticos básicos (individual, social e programático), os quais se relacionam de forma dinâmica e interdependente ${ }^{(5)}$. A vulnerabilidade individual diz respeito a aspectos de ordem cognitiva e comportamental, isto é, considera os comportamentos que podem criar uma maior oportunidade de o indivíduo infectar-se e/ou adoecer, sendo que eles estão associados ao grau de consciência que os mesmos têm da epidemia HIV/Aids e ao seu poder de transformação destas atitudes.

O componente social da vulnerabilidade está relacionado ao acesso que os indivíduos têm às informações, às instituições de saúde e de educação, às condições de bem-estar e lazer, bem como ao poder de influenciar decisões políticas, à possibilidade de enfrentar barreiras culturais e de estar livre de coerções violentas de todas as ordens $^{(13)}$. A vulnerabilidade programática refere-se ao grau de comprometimento do governo com a epidemia da Aids, às ações preventivas e educacionais, aos investimentos e financiamentos em ações assistenciais e preventivas, aos recursos (humanos e físicos) existentes, à qualidade de gerência e monitoramento dos programas, à continuidade e sustentabilidade destas ações, entre outros.

O conceito de vulnerabilidade tem possibilitado, na medida do possível, (re)estruturar ações e políticas governamentais e não-governamentais, auxiliando na diminuição e no controle de novos casos de HIV/Aids. Este referencial tem oportunizado repensar acerca das questões intrínsecas à epidemia, ou seja, que o fato de infectar-se com o HIV ou adoecer de Aids projeta-se para além de aspectos inerentes ao indivíduo e seu comportamento, relacionando-se aos contextos social, cultural, econômico, político, religioso, entre outros. Ele

amplia a necessidade de extrapolar as tradicionais abor-

dagens comportamentalistas das estratégias individuais para a prevenção do HIV, abrindo novas e promissoras perspectivas para o conhecimento e a intervenção sobre a epidemia da Aids ${ }^{(14)}$.

O referencial da vulnerabilidade, então,

busca estabelecer uma síntese conceitual e prática das dimensões sociais, político-institucionais e comportamentais associadas às diferentes susceptibilidades de indivíduos, grupos populacionais e até mesmo nações à infecção pelo HIV(15)

e ao agravamento por Aids. Tem possibilitado, portanto, uma mudança do foco de atenção unicamente centrado no pessoal para contemplar o indivíduo como influenciador e influenciado pelo social e fazendo parte deste, bem como tem oportunizado um reestruturar e reorganizar das ações e políticas preventivas e de educação em saúde.

Por fim, destacam-se algumas dificuldades e limitações presentes ao ter como premissa o referencial da vulnerabilidade: 1) sua utilização no contexto da epidemia da Aids é recente e há necessidade de mais estudos e pesquisas para se compreender melhor seus benefícios e suas limitações; 2) por ser um conceito abrangente, complexo e não ter um foco direcional, pode parecer mais teórico do que prático e isso dificultar a escolha e o delineamento de ações e políticas; e, 3) a vulnerabilidade é multidimensional, apresenta diferentes graus e é dinâmica; as pessoas não são vulneráveis, elas estão vulneráveis sempre a algo, em algum grau e forma, e num certo ponto do tempo e espaço(5).

\section{VULNERABILIDADES AO HIVIAIDS DAS FAMÍLIAS: UM EXERCÍCIO REFLEXIVO}

As famílias, como já salientado, vêm passando por um processo de ressignificação e reestruturação individual e social, tendo em vista as importantes alterações que se operam em sua organização. Conjuntamente, tem-se, também, as transformações culturais, políticas, sociais, religiosas e econômicas que vêm ocorrendo na sociedade, em especial quando se analisa o cenário de mudanças na área da saúde como, por exemplo, as representadas pelo avanço científico e tecnológico, pelo aumento da expectativa de vida, pelas doenças crônicas (hipertensão arterial, diabetes mellitus, Aids) e degenerativas (Alzheimer, Parkinson).

Assim, a partir deste momento, far-se-á, em um movimento de reflexão-abstração, um exercício de aproximação com as interfaces das famílias nos três planos da vulnerabilidade. Este referencial permite lançar um olhar que contempla uma unidade em seus aspectos individual e social; unidade entendida para além do conceito estrito da palavra, mas como uma categoria, que pode ser o indivíduo, um grupo de indivíduos, a família, diversas famílias de uma comunidade ou região, entre outros.

Isto porque,

nascido das lacunas e silêncios que os discursos do fator, grupo e comportamento de risco foram deixando como es- 
pólio indissociável de suas contribuições, esse novo discurso é constitutivamente assim: fragmentário, múltiplo, assistemático, dissonante( ${ }^{(15)}$.

Contudo, ressalta-se que existe uma dinamicidade entre o individual, o coletivo e o programático ${ }^{(5,16)}$, sendo que alguns aspectos podem ser específicos de determinado plano ou pertencer a todos, bem como podem ter sido incluídos em um deles para fins desta reflexão, de nada impedindo sua movimentação.

A fim de alcançar este exercício reflexivo, propõe-se pensar a partir de um exemplo específico de estrutura familiar. Para tanto, será considerado o seguinte caso fictício: Mário, 47 anos, superior completo e funcionário público é casado com Maria, 42 anos, superior incompleto e dona de casa. $O$ casal tem dois filhos: Márcia, 9 anos, estudante da 4a série do ensino fundamental, e Márcio, 18 anos, que está estudando em um curso pré-vestibular. A família é de classe média e tem boas condições de lazer e de vida.

Lançando um olhar ao plano individual da vulnerabilidade, percebe-se que a família é constituída por diferentes indivíduos, que ocupam posições internas também distintas, que têm potencialidades e limitações específicas, que exercem diferentes graus de poder entre si e, portanto, apresentam diversas relações com o contexto HIV/Aids, as quais representam sua vulnerabilidade à infecção e as chances de se defender dela. Podem ser contextualizadas pelos diferentes graus de autonomia, de poder, de consciência e as respectivas ações/atitudes desenvolvidas pelos indivíduos e, assim, constroem a vulnerabilidade da família como unidade, seja para o que tange à prevenção do HIV ou para evitar o adoecimento por Aids.

Fazendo referência à família fictícia, considera-se, por exemplo, que o filho adolescente é mais vulnerável à epidemia HIV/Aids por não apresentar um/a parceiro/a fixo/a, ao passo que o casal pode ser considerado mais vulnerável em virtude da maior dificuldade em negociar o uso do preservativo. Além disso, devido às questões de gênero, as mulheres desta família podem ser consideradas mais vulneráveis, ou a filha menor devido a sua pouca consciência e compreensão em relação à infecção pelo HIV. Estas são apenas algumas das possibilidades de exercício reflexivo relacionado à vulnerabilidade individual deste agrupamento familiar.

No entanto, vale destacar que a vulnerabilidade da família à epidemia HIV/Aids precisa ser compreendida para além do sistema resultante da associação (somatório) das diferentes vulnerabilidades a que estão expostos seus membros. Isto é, a vulnerabilidade individual da família não é resultante, apenas, da soma da vulnerabilidade do indivíduo 1 , com a do indivíduo 2 e do indivíduo 3 , pois há uma dinamicidade, complexidade e movimentação que a torna mais ou menos vulnerável dependendo da situação, do tempo e do momento em análise. Desta forma, compreende-se que a

vulnerabilidade de um grupo à infecção pelo HIV e ao adoecimento é resultado de um conjunto de características dos contextos políticos, econômico e socioculturais que ampliam ou diluem os aspectos relacionados ao plano individual ${ }^{(17)}$.

O plano social apresenta relação próxima com o anterior, pois a vulnerabilidade dos indivíduos que compõem a família está em constante movimento e associação com seu modo de ser social e com o modo de ser de outros indivíduos da coletividade. Porém, em referência à família, esta deve ser percebida como uma unidade pertencente à comunidade, sofrendo influências e influenciando-a ao mesmo tempo. A vulnerabilidade social da família revela-se pela maior ou menor facilidade de acesso aos sistemas de educação e saúde, às condições sócio-econômicas que a situam na sociedade, ao maior ou menor poder que exerce no entorno social, as suas (im)possibilidades de lazer, de liberdade, de autonomia, entre outros aspectos.

Tendo como exemplo o caso anterior, pode-se pensar a vulnerabilidade social daquela família em relação aos serviços de saúde, ou seja, se conseguem, quando precisam, de consultas e exames, se tem suas dificuldades e necessidades atendidas, se há programas de prevenção ao HIV/Aids e ações de educação em saúde (para homens, mulheres, crianças, adolescentes, idosos). Ainda, pode-se considerar o grau de liberdade que esta família tem com outras famílias para discutir e decidir questões de interesse comum, sua relação com as instituições religiosas, a existência de projetos na escola que objetivem criar uma rede familiar e social de apoio para o enfrentamento de situações adversas, entre outros aspectos.

Necessita-se, então, refletir acerca da interdependência entre o plano individual e o social, quando se está analisando a família. Ou seja, ela é constituída por indivíduos que apresentam vulnerabilidades específicas, sendo as relações existentes entre estas que acabarão por indicar o menor ou maior grau de vulnerabilidade (individual) da família em relação a um fenômeno em certo tempo e espaço. Ainda, este grupo familiar constitui, juntamente com outros grupos familiares, uma comunidade, sendo que a forma como cada um deles estabelece aproximações e relações com a sociedade, o modo como atuam e inserem-se nos seus níveis institucionais, o que auxiliará na identificação de uma maior ou menor vulnerabilidade (social) da família.

O plano programático de análise considera as políticas e programas governamentais relacionados às famílias, o quanto procuram mobilizar estes agrupamentos para o desenvolvimento de ações e atitudes que visem a mudanças individual e coletiva, o quanto mobilizam as famílias a 
participarem de forma autônoma e responsável em seu entorno social e, a partir daí, refletir acerca de sua vulnerabilidade ao HIV/Aids.

Em relação ao exemplo, a vulnerabilidade programática daquela família está relacionada, no âmbito dos serviços de saúde, à existência de políticas governamentais na área da prevenção e promoção da saúde, à disponibilidade de recursos para a continuidade destas ações e o poder de sustentabilidade local de projetos integrados com outras instituições (escola, ONG). Também, pode ser considerada a capacidade de abrangência destas ações nos diversos níveis (federal, estadual, municipal e local), a capacitação da equipe para desenvolver os projetos, a atuação de programas de educação em saúde relacionados a cada um dos membros familiares em seus diferentes aspectos (físicos, cognitivos, de gênero, de idade), entre outros.

Assim, em meio a este exercício, é importante considerar que as análises e reflexões apresentadas tiveram como exemplo um tipo específico de grupo familiar e que $o$ apresentado tem apenas por objetivo possibilitar o exercício de se pensar alguns aspectos dos três planos da vulnerabilidade aplicados à família. No entanto, outras seriam as reflexões destacadas caso estivesse em análise uma família constituída por dois indivíduos do mesmo sexo - com ou sem filhos - ou, então, uma família formada por mais indivíduos, com diferentes idades e que apresentam, por exemplo, outros tipos de doenças e de inclusão na sociedade.

Portanto, em relação à epidemia HIV/Aids, é relevante considerar, ainda, questões como a orfandade a que estão expostas as crianças e adolescentes e sua consequente institucionalização, os silêncios existentes no interior das famílias em relação ao diagnóstico de seus membros, o pacto de silêncio ${ }^{(9)}$ familiar relacionado ao HIV/Aids para o que tange à comunidade, aos serviços de saúde e à escola/creche, a presença cada vez mais comum de relacionamentos entre indivíduos sorodiscordantes, a existência (ou não) de ações e políticas de prevenção, diagnóstico e assistência, que são aspectos que interferem, aumentando ou diminuindo, a vulnerabilidade familiar à epidemia HIV/Aids.

\section{REFERÊNCIAS}

1. Gomes MA, Pereira MLD. Família em situação de vulnerabilidade social: uma questão de políticas públicas. Ciênc Saúde Coletiva. 2005;10(2):357-63.

2. Serapioni M. O papel da família e das redes primárias na reestruturação das políticas sociais. Ciênc Saúde Coletiva. 2005;10 Supl 1:243-53.

3. Angelo M, Bosso RS, Rossato LM, Damião EBC, Silveira AO, Castilho AMCM et al. Família como categoria de análise e campo de investigação em enfermagem. Rev Esc Enferm USP. 2009;43(n.esp 2):1337-41.

\section{CONCLUSÃO}

Este artigo aponta para a necessidade de se utilizar o referencial teórico-metodológico da vulnerabilidade não só em relação aos indivíduos, mas também às famílias, para que se possa planejar estratégias que contemplem sua pluralidade e dinamicidade social. Isto porque ao se vislumbrar que existem aspectos que tornam as diferentes famílias mais ou menos susceptíveis à epidemia HIV/Aids, bem como que entre os planos há uma dependência e complexidade, será possível a construção de ações e políticas que abranjam além das questões técnico-científicas, aspectos subjetivos, intersubjetivos e emocionais.

Acredita-se, então, que é necessário considerar e definir os contextos de intersubjetividade que geram vulnerabilidades, bem como (e articuladamente) considerar e definir contextos intersubjetivos que favoreçam a construção e implementação de respostas que minimizem estas mesmas vulnerabilidades ao HIV/Aids. Isto, atualmente, representa um dos mais novos, decisivos e importantes desafios para a prevenção e cuidado frente à epidemia. Partindo desta perspectiva, poder-se-á entender as necessidades, limitações e potencialidades de cada pessoa e de cada família, em termos individuais e coletivos, educacionais e preventivos, para, então, desenvolver um cuidado humanístico e resolutivo nas situações de saúde e de doença.

Concluindo, compreende-se como essencial perceber que, para além de uma vulnerabilidade inerente ao ser humano como único e singular em seu modo de viver e de inserir-se socialmente, também há uma vulnerabilidade (em seus três planos) em que estão inseridas as famílias. Este referencial quando relacionado ao agrupamento familiar precisa ser pensado a partir da perspectiva de que ele é composto por diferentes indivíduos, que desempenham, sofrem e apresentam distintas influências e mobilidades no contexto social e, ainda, tem relação com os incentivos e investimentos políticos e programáticos do governo. Será o conjunto destas situações vivenciadas e experienciadas pelas famílias que determinarão sua maior ou menor vulnerabilidade frente à epidemia HIV/Aids.

4. Calazans GJ, Saletti Filho HC, França Junior I, Ayres JRCM. O conceito de vulnerabilidade. In: Padoin SMM, Paula CC, Schaurich D, Fontoura VA, organizadores. Experiências interdisciplinares em Aids: interfaces de uma epidemia. Santa Maria: Ed. da UFSM; 2006. p. 43-62.

5. Ayres JRCM, França Junior I, Calazans GJ, Saletti Filho HC. O conceito de vulnerabilidade e as práticas de saúde: novas perspectivas e desafios. In: Czeresnia D, Freitas CM, organizadores. Promoção da saúde: conceitos, reflexões, tendências. Rio de Janeiro: FIOCRUZ; 2003. p. 117-39. 
6. Osório LC. Casais e família: uma visão contemporânea. Porto Alegre: Artmed; 2002.

7. Brasil. Ministério da Saúde. Secretaria de Políticas de Saúde. Programa Nacional de DST e Aids. Brasília; 2009.

8. França Junior I, Doring M, Stella IM. Crianças órfãs e vulneráveis pelo HIV no Brasil: onde estamos e para onde vamos? Rev Saúde Pública. 2006;40 Supl 1:23-30.

9. Padoin SMM. A possibilidade de integrar a família ao cuidado. In: Padoin SMM, Paula CC, Schaurich D, Fontoura VA, organizadores. Experiências interdisciplinares em Aids: interfaces de uma epidemia. Santa Maria: Ed. da UFSM; 2006. p. 289-302.

10. Pettengill MAM, Angelo M. Identificação da vulnerabilidade da família na prática clínica. Rev Esc Enferm USP. 2006;40(2):280-5.

11. Schaurich D, Coelho DF, Motta MGC. A cronicidade no processo saúde-doença: repensando a epidemia da Aids após os anti-retrovirais. Rev Enferm UERJ. 2006;14(3): 455-62.

12. Nichiata LYI, Bertolozzi MR, Takahashi RF, Fracolli LA. The use of the "vulnerability" concept in the nursing area. Rev Latino Am Enferm. 2008;16(5):923-8.
13. Meyer DEE, Mello DF, Valadão MM, Ayres JRCM. "Você aprende. A gente ensina?" Interrogando relações entre educação e saúde desde a perspectiva da vulnerabilidade. Cad Saúde Pública. 2006;22(6):1335-42.

14. Reis RK, Gir E. Vulnerability and prevention of sexual HIV transmission among HIV/Aids serodiscordant couples. Rev Esc Enferm USP [Internet]. 2009 [cited 2009 Oct 15]. 15];43(3):662-9. Available from: http://www.scielo.br/pdf/ reeusp/v43n3/en_a23v43n3.pdf

15. Ayres JRCM, França Junior I, Calazans GJ, Saletti F. Vulnerabilidade e prevenção em tempos de Aids. Parker R, Barbosa RM, organizadores. Sexualidade pelo avesso: direitos, identidades e poder. São Paulo: Ed. 34; 2000. p. 49-73.

16. Ayres JRCM. Práticas educativas e prevenção de HIV/Aids: lições aprendidas e desafios atuais. Interface Comun Saúde Educ. 2002;6(11):11-24.

17. Buchalla CM, Paiva V. Da compreensão da vulnerabilidade social ao enfoque multidisciplinar. Rev Saúde Pública. 2002;36 Supl 4:117-9. 